\title{
Outcomes of Patients Treated With Noninvasive Ventilation by a Medical Emergency Team on the Wards
}

\author{
Imran Khalid MD, Nahid Sherbini MD, Ismael Qushmaq MD, Mohammad R Qabajah RN, \\ Amina Nisar MD, Tabindeh J Khalid MD, and Wasfy J Hamad MD
}

\begin{abstract}
BACKGROUND: Initiation of noninvasive ventilation (NIV) on the wards is not universally accepted. Medical emergency teams (METs) provide acute care and monitoring to deteriorating patients on the general wards. Whether it is safe for an MET to start NIV in ward patients with respiratory distress remains unclear. METHODS: We evaluated 1,123 MET calls in 30,217 ward patients between January 2009 and June 2011 from the prospectively maintained MET database in our tertiary care hospital. We identified ward patients with acute desaturation $(<90 \%)$ and tachypnea (breathing frequency $>28$ breaths/min), for whom an MET was called. Subjects transferred to the ICU at the end of an MET call were excluded. The remaining ward subjects were divided into 2 groups: patients who were not started on NIV by the MET; versus patients who were started on NIV by the MET. The primary outcome was endotracheal intubation or ICU transfer within 48 hours of MET activation. Secondary outcome measures were 28-day mortality and ICU mortality. RESULTS: Two hundred thirty-eight MET subjects met the study criteria, and 109 immediate ICU transfers were excluded. Of the remaining 129 ward subjects, 54 were in the NIV group, and 75 in the no-NIV group. The NIV group subjects were sicker (mean Acute Physiology and Chronic Health Evaluation II score 17.6 \pm 5.1 versus $14.4 \pm 5, P<.001)$. Subjects with pulmonary edema, COPD exacerbation, or asthma exacerbation were more likely, while those with pneumonia were less likely to be placed on NIV. The primary outcome was reached in $2 / 54(3.7 \%)$ of the NIV subjects and $12 / 75(16 \%)$ of the no-NIV subjects $(P=.03)$. There was no significant difference $(P>.30)$ between the groups in 28 -day mortality $(7.4 \%$ vs $13.3 \%)$ or ICU mortality $(3.7 \%$ vs $8 \%)$. CONCLUSIONS: In selected ward patients, especially those with COPD or pulmonary edema, NIV can be safely initiated by an MET. Key words: medical emergency team; noninvasive ventilation; ward patients; mortality; tachypnea. [Respir Care 2014;59(2):186-192. () 2014 Daedalus Enterprises]
\end{abstract}

Introduction

Noninvasive ventilation (NIV) delivered via oronasal or nasal mask is an effective technique in the management of

\footnotetext{
The authors are affiliated with the Department of Medicine, King Faisal Specialist Hospital and Research Center, Jeddah, Saudi Arabia, with the exception of Dr Nisar, who is affiliated with Oakwood Hospital and Medical Center, Dearborn, Michigan, and Dr Hamad, who is affiliated with the Division of Pulmonary and Critical Care, John D Dingell Veterans Affairs Medical Center, Detroit, Michigan. Dr Khalid is also affiliated with the Division of Pulmonary and Critical Care, John D Dingell Veterans Affairs Medical Center, Detroit, Michigan.
}

The authors have disclosed no conflict of interest.

Dr Khalid presented a version of this report at the International Conference of the American Thoracic Society, held May 13-18, 2011, in Denver, Colorado. selected patients with respiratory failure. ${ }^{1,2}$ In patients with hypercapnic respiratory insufficiency NIV improves symptoms, decreases the need for invasive ventilation, and reduces the duration of hospitalization and mortality. ${ }^{2-6}$ NIV is also used for managing respiratory symptoms associated with acute cardiogenic pulmonary edema, and minimizes

See the Related Editorial on Page 303

the need for intubation in these patients. ${ }^{7}$ Investigators have also used NIV in asthma, pneumonia, neuromuscular disease, post-extubation, and hypoxemic and postoperative acute respiratory failure, with varying success. ${ }^{8-15}$

The timing and location of initiation of NIV has been evaluated by investigators. Early commencement of NIV in appropriate patients is associated with better outcomes, 
because delay can adversely affect the patient and increase the need for invasive ventilation. ${ }^{2,16}$ Application of NIV in various locations, including pre-hospital, emergency department, ICU, step-down units, and general wards, has also been studied. ${ }^{17-20}$ Because of lack of monitoring and adequate staffing, initiation of NIV is not universally accepted on the wards. ${ }^{1}$ This is despite the presence of some supportive data that starting NIV on the wards may decrease the need for intubation and mortality. ${ }^{21-24}$ Nonetheless, the concern for starting NIV without monitoring on the wards is legitimate, as non-responding patients can go unnoticed and may deteriorate suddenly in the absence of close observation. ${ }^{1,25}$

Medical emergency teams (METs) provide immediate critical care expertise in evaluating, monitoring, treating, and triaging general ward patients. ${ }^{26}$ In some hospitals, patients on the wards can be started on NIV during MET evaluation. These patients are different from the ward patients in the aforementioned studies, as they are evaluated, treated, and triaged promptly by the MET in a timely manner for their acute symptoms. Also, if the MET deems the patient stable to stay on the ward with NIV, the decision is usually made after some evidence of clinical stability and/or follow-up. So MET initiation of NIV on the wards appears promising and provides an intermediate solution to the lack of available monitored beds. To the best of our knowledge, only 2 studies have evaluated this practice. Cabrini et al applied NIV in a wide variety of settings outside the ICU, with a high success rate and few complications. ${ }^{27}$ However, in another study, by Schneider et al, $60 \%$ of the patients placed on NIV were ultimately transferred to an ICU or high-dependence unit, which suggests against this practice. ${ }^{28}$ These dissimilarities led us to investigate this question further.

We conducted this study to evaluate the outcome of NIV initiated for respiratory distress on the general wards in the context of MET encounters.

\section{Methods}

The ethical approval for the study was obtained from the institutional review board of our hospital, which is a 429-bed, Joint Commission International and Magnet accredited, tertiary care teaching facility, with active bone marrow and limited solid organ transplant programs, along with expert medical and surgical subspecialties. It has a fully equipped ICU with 18 combined medical-surgical beds, but no high-dependence or step-down unit. Data were

Correspondence: Imran Khalid MD, Department of Medicine, King Faisal Specialist Hospital and Research Center, Jeddah, 21499, Saudi Arabia. E-mail: doc_ik@yahoo.com.

DOI: $10.4187 /$ respcare. 02515

\section{QUICK LOOK}

\section{Current knowledge}

Noninvasive ventilation (NIV) use outside the ICU is controversial and has had varying success, depending on the severity of patient illness and the goals of therapy. Early application of NIV in the general wards, by a rapid-response team, to prevent ICU readmission, might be safe and effective.

\section{What this paper contributes to our knowledge}

Early application of NIV in the general wards by rapidresponse teams significantly decreased the need for intubation, with no impact on mortality.

retrieved regarding all the patients who had an episode of acute desaturation (saturation $<90 \%$ ) and tachypnea (breathing frequency $>28$ breaths $/ \mathrm{min}$ ) on the general wards in our hospital between January 2009 and June 2011. The same rule applied for patients who were already on oxygen.

Since 2007 the hospital has had a rapid-response alert system for patients in non-critical areas showing any signs of hemodynamic instability. Patients receiving palliative care or who have do-not-attempt-resuscitation orders are excluded from the rapid-response service, per institution policy. Ward nurses are the ones who usually initiate the system, via an overhead announcement system, and an MET responds within $5 \mathrm{~min}$ and attends to the patient. In our hospital an MET comprises an internal medicine physician (either a junior staff or a senior medical resident), a designated critical care nurse who carries an emergency medication box, a respiratory therapist, and a standby pharmacist for prompt delivery of any additional medications. The MET manages the patient along with the primary team, until the patient is stabilized or transferred to the ICU. In patients with respiratory distress the MET can initiate NIV via oronasal mask. The decision to initiate NIV is made by the MET physician, and is based on his/her clinical judgment on whether NIV is suitable in the given clinical scenario. There is no protocol in the hospital's MET policy to guide the MET physician to initiate NIV. Patients with contraindications to NIV (eg, recent esophageal, facial, or cranial trauma or surgery; markedly decreased level of consciousness; severe hemodynamic instability; persistent lack of cooperation; arrhythmia; acute ischemia; or active upper gastrointestinal bleeding) are not given a trial of NIV.

During the study period the NIV was set up and adjusted by the respiratory therapist, per hospital policy. The ventilators used during the study period for NIV included BiPAP Auto-SV (Philips Respironics, Murrysville, Pennsylvania), BiPAP vision (Philips Respironics, Murrysville, Pennsylvania), and V-60 ventilator (Philips Respironics, 
Murrysville, Pennsylvania, from mid-2010). The ventilation modes used were CPAP, bi-level positive airway pressure, average volume-assured pressure support, or pressure control ventilation. Average volume-assured pressure support and pressure control ventilation were used as back-up modes in subjects who did not tolerate or did not respond initially to CPAP or bi-level positive airway pressure. The CPAP was initiated at $5 \mathrm{~cm} \mathrm{H}_{2} \mathrm{O}$ and titrated up to a maximum of $20 \mathrm{~cm} \mathrm{H}_{2} \mathrm{O}$, based on the subject's condition. The bi-level positive airway pressure was started with an inspiratory pressure of 8-10 and an expiratory pressure of $4-5 \mathrm{~cm} \mathrm{H}_{2} \mathrm{O}$, up to a maximum inspiratory pressure of $20 \mathrm{~cm} \mathrm{H}_{2} \mathrm{O}$. The pressures were modified by the respiratory therapist to achieve acceptable tidal volumes, breathing frequency, and minute ventilation. If the subject was stabilized on the ward, the MET officially signed off and the subject was managed, with or without NIV, by the primary physician, as appropriate without any additional monitoring. The primary physicians were the ones who eventually discontinued NIV or made the decision to intubate per their clinical judgment. However, in cases where the subject was deteriorating from the onset of the MET call, or there was a lack of response to initial treatment by the MET, the intensivist was involved during the MET encounter for subject evaluation and ICU transfer. The MET signed off once the ICU transfer was complete.

\section{Subjects and Study Variables}

During the study period we evaluated all adult patients $\geq 18$ years old for whom MET was activated. Subjects with acute tachypnea and desaturation were included. Acute tachypnea was defined as a breathing frequency of $>28$ breaths/min, and desaturation as $\mathrm{S}_{\mathrm{pO}_{2}}$ of $<90 \%$, per the hospital's MET activation criteria. The same rule applied for subjects already on oxygen. Subjects on oxygen were included if they had acute tachypnea and desaturation while on oxygen. The subjects were identified from the MET comprehensive database. These MET encounters were maintained prospectively, as part of hospital quality control processes, and subject information regarding the encounters was completed in real time by the MET team. The missing information not recorded in the MET encounter sheets was collected retrospectively from the electronic medical records and subject files. The subjects were admitted from the general wards, which are divided by specialty in our hospital. The wards included general medical/ surgical, nephrology, oncology (including hematological malignancies), cardiology, and neurology. These wards are not monitored, and the routine is that vital signs (including $\mathrm{S}_{\mathrm{pO}_{2}}$ ) are measured every 4 hours, or sooner if clinically indicated. Patients admitted to the ICU from the other critical care units (eg, cardiothoracic), operating room, or emergency department were excluded because the METs do not serve those areas.

We excluded patients with tachypnea and desaturation for whom MET was not activated, patients for whom the MET was called erroneously, tracheostomized patients, patients recently (within $24 \mathrm{~h}$ ) admitted to the wards from the emergency room, and palliative-care-only patients. We also excluded the patients who were immediately transferred to the ICU at the end of MET evaluation. Patients who remained on the wards were divided into 2 groups: those who were placed on NIV during the MET encounter, and those who were not placed on NIV but were kept on the ward. Both groups received unrestricted medical therapy per the discretion of the MET and the primary team.

We recorded age, sex, underlying chronic diseases, arterial blood gas values at the time of the MET evaluation, Acute Physiology and Chronic Health Evaluation II (APACHE II) scores at the time of the MET assessment (for laboratory data we took the worst values from the 6 hours around the MET call), and the reasons for the symptoms. For APACHE II score, if data were missing, the APACHE II score was recorded as normal. ${ }^{29}$

\section{Outcomes and Analysis}

The primary outcome variable was endotracheal intubation or ICU transfer within 48 hours of symptoms onset and MET activation. Secondary outcome measures were 28-day mortality and ICU mortality. The data were analyzed using the Student $t$ test, one-way analysis of variance, and the Pearson chi-square test, as appropriate. Differences were considered significant at $P<.05$.

\section{Results}

There were 1,123 MET calls for 30,217 ward patients during the study period. Out of these, 238 were for acute tachypnea and desaturation. Twenty-six patients had an erroneous MET call initiated because of measurement error, were recently admitted from the emergency room, or were on palliative care only, and those 26 were excluded. Eighty-three subjects were immediately transferred to the ICU by the end of MET evaluation, and those 83 were also excluded. However, we did look at the intubation rate among that group, and it was $51 \%(n=42 / 83)$. The remaining 129 subjects were analyzed and divided into the NIV and no-NIV study groups (Fig. 1).

The baseline demographics of the 2 groups are shown in Table 1. There was no statistical difference in age, sex, or underlying disease. However, the NIV group subjects had lower arterial blood $\mathrm{pH}$, higher bicarbonate, were more hypercapnic, had better symptomatic improvement in their breathing frequency, and MET spent more time with them during the MET call (Table 2) The NIV group also had 


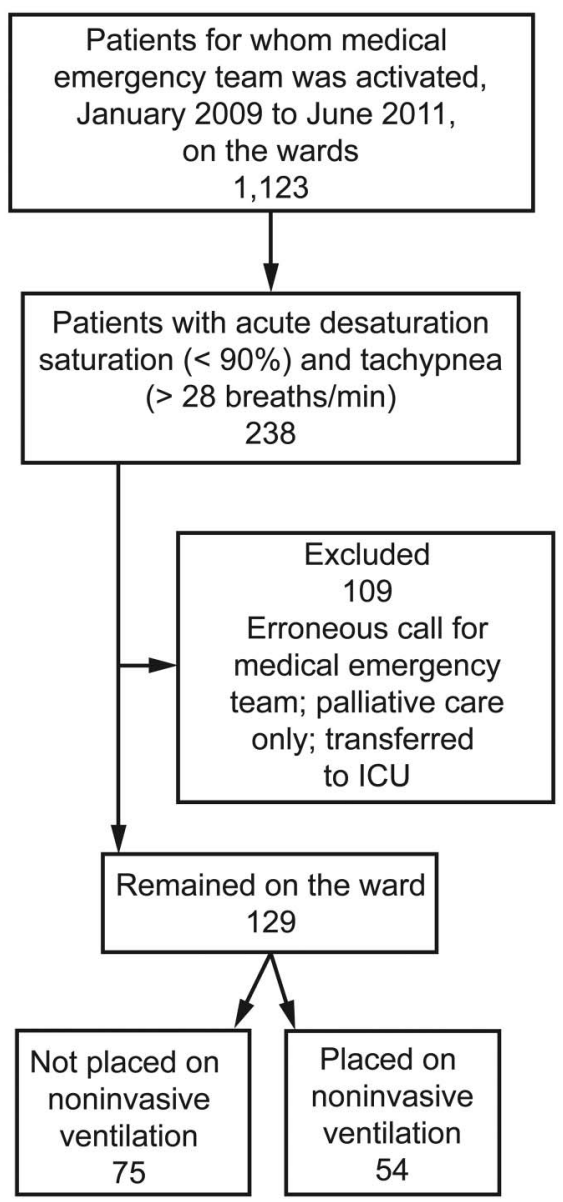

Fig. 1. Flow chart.

Table 1. Baseline Characteristics

\begin{tabular}{lccc}
\hline \hline & $\begin{array}{c}\text { No NIV } \\
(n=75)\end{array}$ & $\begin{array}{c}\text { NIV } \\
(n=54)\end{array}$ & $P$ \\
\hline Age, mean \pm SD y & $62 \pm 16$ & $65 \pm 18$ & .30 \\
Male & $42(56)$ & $29(53)$ & .70 \\
Female & $33(44)$ & $25(47)$ & .70 \\
Chronic dialysis & $15(20)$ & $10(19)$ & .80 \\
Malignancy & $11(15)$ & $6(11)$ & .60 \\
Immunosuppression & $8(11)$ & $3(6)$ & .60 \\
Congestive heart failure & $17(23)$ & $18(33)$ & .10 \\
Liver failure & $6(8)$ & $4(7)$ & .90 \\
Pulmonary disease & $15(20)$ & $16(30)$ & .10 \\
None & $17(23)$ & $11(20)$ & .80 \\
& & & \\
Values are number and percent unless otherwise indicated. Some subjects had multiple & \\
diseases, so the percentages sum to $>100 \%$. & & \\
NIV $=$ noninvasive ventilation & & & \\
&
\end{tabular}

higher APACHE II scores (Fig. 2) Subjects with pulmonary edema, COPD, or asthma exacerbation were more likely to be placed on NIV on the ward. Subjects with pneumonia or aspiration, who were deemed stable enough not to be intubated at the initial MET encounter and stayed on the wards, were less likely to be given NIV (Table 3)

For the primary outcome, we found that the NIV group had a lower rate of intubation or ICU transfer: $3.7 \%$ versus $16 \%(P=.03$, Fig. 3$)$ There was no difference in the time to the primary outcome (see Table 2 ), and no significant difference in 28-day or ICU mortality (Fig. 4). The causes of death are listed in Table 4. In regards to major complications from NIV, only one subject vomited and aspirated in the NIV group. We found no documentation of minor complications such as air leak or claustrophobia. Usually these are taken care of by the respiratory therapist or the physician.

\section{Discussion}

In an ideal situation, the best place to initiate NIV is a monitored setting with a good nurse-to-patient ratio. ${ }^{30}$ However, with the growing shortage of ICU beds and lack of high dependence units in many hospitals, ${ }^{19,25,31}$ the options are limited to either delaying NIV initiation or to starting it on the ward. Delay can result in patient deterioration and reduce the chance of NIV success. ${ }^{2,16}$ Studies have shown, with varying success, that NIV on the ward is feasible in selected populations. However, generalizing NIV use in all patients may not be appropriate.

We found in our study that after MET encounters for true tachypnea and desaturation, 4 out of 10 subjects were immediately transferred to the ICU. Out of the remaining ward subjects, another 4 out of 10 were placed on NIV for their symptoms and clinical condition. Even though the NIV subjects were sicker (as per APACHE II score) than the non-NIV subjects, they had significantly less intubation and transfer to the ICU, and NIV did not adversely impact their mortality.

Our study differs from the studies by Cabrini et al ${ }^{25}$ and Schneider et al. ${ }^{28}$ The Cabrini study was not done in a true MET context, where a single anesthesiologist worked as the MET to manage NIV. Cabrini included around $40 \%$ emergency department patients, which are not served by MET in our hospital. However, their percentage of patients with COPD and pulmonary edema (61\%) and the severity of acidosis ( $\mathrm{pH} 7.29$ ) were similar to ours. In the Schneider study the patients were evaluated in a true MET context, but Schneider did not exclude immediate ICU transfers (60\% of their total patients), which resulted in higher mortality $(23.6 \%)$ among their patients without limitation of treatment, as compared to Cabrini (12\%) and our (8\%) study. Also, Schneider had a lower percentage of patients with COPD and pulmonary edema (39\%).

Two practices we observed in our study, that sicker patients were immediately transferred to ICU without a trial of NIV on the ward, and that NIV was used in selected subjects, conform to the accepted practice regarding NIV. This explains the good outcomes in our NIV subjects on the wards. The MET did initiate the NIV in our subjects, but after initial stabilization they signed off, and the 
Table 2. Patient and Outcome Variables

\begin{tabular}{|c|c|c|c|}
\hline & $\begin{array}{l}\text { No NIV } \\
(n=75)\end{array}$ & $\begin{array}{c}\text { NIV } \\
(n=54)\end{array}$ & $P$ \\
\hline Arterial $\mathrm{pH}$ & $7.39 \pm 0.12$ & $7.27 \pm 0.15$ & $<.001$ \\
\hline $\mathrm{P}_{\mathrm{CO}_{2}}, \mathrm{~mm} \mathrm{Hg}$ & $35 \pm 9$ & $57 \pm 11$ & $<.001$ \\
\hline Bicarbonate, $\mathrm{mmol} / \mathrm{L}$ & $22.8 \pm 4.2$ & $25.1 \pm 5.0$ & .005 \\
\hline \multicolumn{4}{|c|}{$\begin{array}{l}\text { NIV pressures at end of MET call, } \mathrm{cm}_{2} \mathrm{O} \\
(9 \text { on CPAP, } 35 \text { on BPAP, } 7 \text { on other, } \\
3 \text { data missing) }\end{array}$} \\
\hline CPAP & NA & $10.8 \pm 2.3$ & NA \\
\hline BPAP inspiratory pressure & NA & $15.3 \pm 2.1$ & NA \\
\hline BPAP expiratory pressure & NA & $7.4 \pm 1.9$ & NA \\
\hline \multicolumn{4}{|l|}{ Breathing frequency, breaths/min } \\
\hline At start of MET call & $32.4 \pm 4.1$ & $33.1 \pm 3.9$ & .30 \\
\hline At end of MET call & $26.3 \pm 3.1$ & $24.6 \pm 4.3$ & .01 \\
\hline MET call duration, min & $82 \pm 26.7$ & $118 \pm 34.1$ & $<.001$ \\
\hline Duration of NIV, h & NA & $6.7 \pm 3.9$ & NA \\
\hline Time to primary outcome, $\mathrm{h}$ & $8.9 \pm 5.2$ & $10.5 \pm 3.5$ & .70 \\
\hline Hospital stay, d & $12.1 \pm 5.3$ & $13.3 \pm 4.6$ & .20 \\
\hline \multicolumn{4}{|l|}{$\begin{array}{l}\text { Values are mean } \pm \text { SD. } \\
\text { NIV }=\text { noninvasive ventilation } \\
\text { MET }=\text { medical emergency team } \\
\text { BPAP = bi-level positive airway pressure } \\
\text { NA }=\text { not applicable }\end{array}$} \\
\hline
\end{tabular}

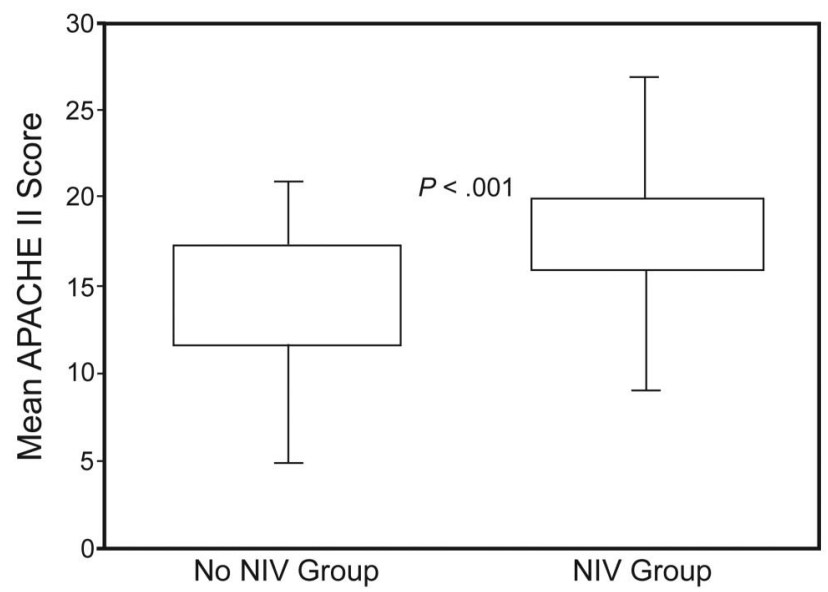

Fig. 2. Acute Physiology and Chronic Health Evaluation II (APACHE II) scores at time of medical emergency team evaluation. In each data bar, the bottom and top of the bar represent the interquartile range values (Q1 and Q3), and the whisker bars represent the minimums and maximums. NIV $=$ noninvasive ventilation.

subjects were kept on NIV with regular ward staffing and no additional monitoring. Our results suggest that this practice is safe in selected patients: 54 subjects were successfully managed on the ward with NIV, resulting in better resource utilization and cost savings. ${ }^{32}$

Our no-NIV subjects had higher rates of intubation and transfer to the ICU than our NIV group. Several fac-
Table 3. Reasons for Medical Emergency Team Activation

\begin{tabular}{lccc}
\hline \hline & $\begin{array}{c}\text { No NIV } \\
(n=75)\end{array}$ & $\begin{array}{c}\text { NIV } \\
(n=54)\end{array}$ & $P$ \\
\hline COPD/asthma exacerbation & $7(9)$ & $14(26)$ & .01 \\
Pulmonary edema & $15(20)$ & $21(39)$ & .01 \\
Pneumonia/aspiration pneumonitis & $23(31)$ & $6(11)$ & .008 \\
Pleural effusion & $10(13)$ & $3(6)$ & .20 \\
Pulmonary embolism & $7(9)$ & $2(4)$ & .40 \\
Other & $13(17)$ & $8(15)$ & .70
\end{tabular}

Values are number and percent. Due to rounding, the percentages may not sum to 100 . $\mathrm{NIV}=$ noninvasive ventilation

tors might explain those findings. The MET spent considerably more time with the NIV subjects, which might have resulted in better outcomes because of a higher level of initial monitoring and attention. ${ }^{33}$ The no-NIV group had lower bicarbonate, reflecting the presence of non-respiratory problems contributing to their tachypnea. This can explain why pneumonia and sepsis were the main reasons for the outcomes in the no-NIV group. Whether the no-NIV subjects would have benefited from NIV (as they were felt not to be sick enough to be intubated in the MET encounter) or would have benefited from being transferred to the ICU immediately, is unclear, and future studies should focus on such patients. Our focus mainly was on the safety and outcome of the NIV subjects, which in the context of MET calls seemed to do ok. 


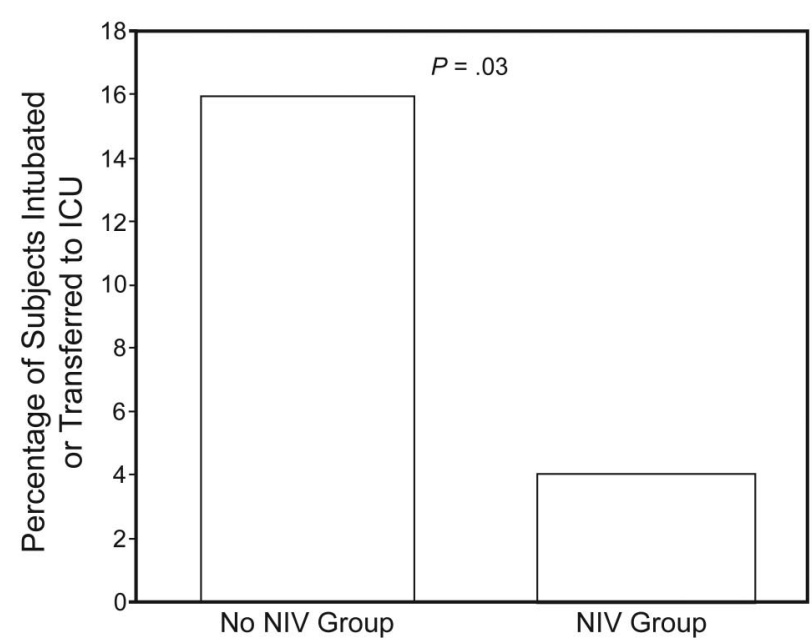

Fig. 3. Percentage of subjects who had the primary outcome of intubation or ICU transfer. NIV = noninvasive ventilation.

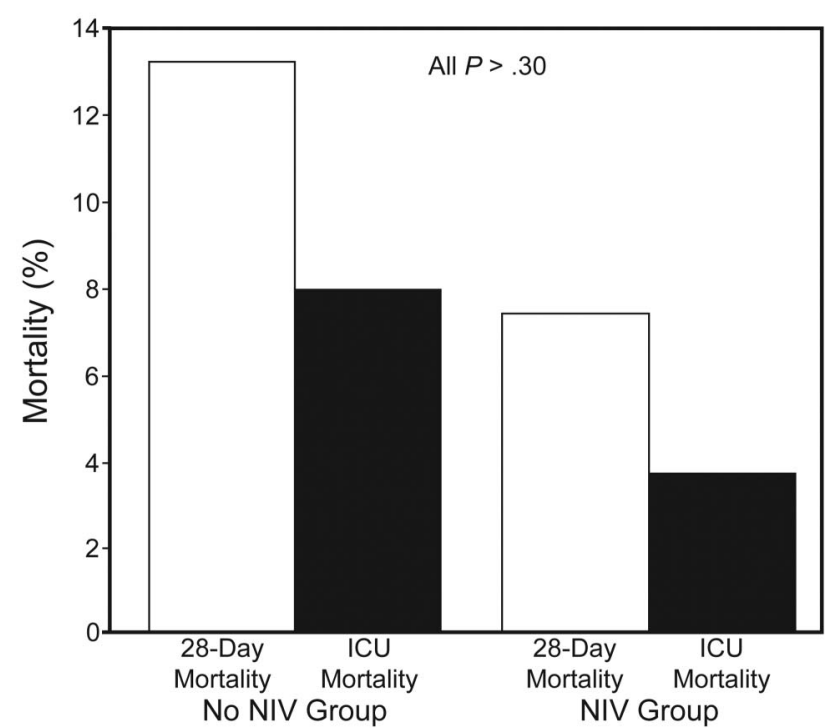

Fig. 4. 28-day mortality and ICU mortality. NIV = noninvasive ventilation.

Our study has a few clinical implications. It emphasizes immediate triaging to the ICU of high-risk patients with impending severe respiratory failure without a trial of NIV on the ward. Both in our study and Schneider et al's, such patients had a high rate of intubation. ${ }^{28}$ However, our results show that not all the patients requiring NIV need to go to a higher level of care, as was suggested by Schneider et al. NIV can be safely initiated by the MET in selected patients, especially those with COPD, asthma, or pulmonary edema. Such patients can stay on the ward unmonitored, even after the MET signs off. This practice provides a safety net for ward patients, by brief initial monitoring by the MET: a practice that can help alleviate concerns regarding the safety of such patients. The ward subjects in our
Table 4. Reasons for Intubation and Causes of Death

\begin{tabular}{lcc}
\hline \hline & No NIV & NIV \\
\hline Reason for intubation/ICU transfer & 6 & \\
$\quad$ Pneumonia & 4 & 1 \\
Sepsis & 1 & 1 \\
Pulmonary edema & 1 & 0 \\
Pleural effusion & & 0 \\
Cause of death & 1 & \\
Malignancy & 1 & 1 \\
End-stage lung disease & 6 & 2 \\
Sepsis (including pneumonia) & 1 & 0 \\
Congestive heart failure & 1 & 0 \\
Liver failure & & \\
& & \\
NIV = noninvasive ventilation & & \\
\hline
\end{tabular}

study, who deteriorated in both groups, did so within an average of 9-10 hours. So we propose that METs follow these patients for that duration, as an additional precaution. The logistical and financial implications of these suggestions seem better than an actual ICU transfer in these patients.

Our study has a few limitations. First of all it is a retrospective study of prospectively gathered data, and has the shortcomings of such studies. The triaging capabilities of different physicians vary, and that can impact the outcome. ${ }^{34}$ This was also a single-center study, and the outcomes might be better or worse for similar patients at other institutions. Our METs were led by an internal medicine physician accompanied by a respiratory therapist. A MET without a respiratory therapist might have different results. Our population consisted of tertiary care patients, and results may differ in other patient populations.

We do not have outcome data on patients who met the MET criteria but for whom a MET was not called. The safety and success of NIV administered in a general ward is determined by an appropriate patient selection, identifying those who can benefit from NIV and those who are at risk of NIV failure. The retrospective nature of the study limited our ability to identify which triage characteristics the MET physicians used for initiation or non-initiation of the NIV. Future studies should be designed to answer these important questions.

\section{Conclusions}

Based on our results we suggest that, for selected patients, especially those with COPD or asthma exacerbation or pulmonary edema, NIV can be safely started in the context of an MET evaluation. Not all patients on NIV need to be transferred to an ICU. Even in the absence of close monitoring on the ward, our NIV subjects had lower rates of intubation and transfer to the ICU, without adverse 


\section{Outcomes of Patients Treated With Noninvasive Ventilation by a Medical Emergency Team}

impact on mortality. Future studies should validate these results and focus on improving MET systems that can accurately triage such patients.

\section{REFERENCES}

1. Hill NS. Where should noninvasive ventilation be delivered? Respir Care 2009;54(1):62-70.

2. Nava S, Navalesi P, Conti G. Time of non-invasive ventilation. Intensive Care Med 2006;32(3):361-370.

3. Celikel T, Sungur M, Ceyhan B, Karakurt S. Comparison of noninvasive positive pressure ventilation with standard medical therapy in hypercapnic acute respiratory failure. Chest 1998;114(6):1636-1642.

4. Brochard L, Mancebo J, Wysocki M, Lofaso F, Conti G, Rauss A, et al. Noninvasive ventilation for acute exacerbations of chronic obstructive pulmonary disease. N Engl J Med 1995;333(13):817-822.

5. Ambrosino N, Vagheggini G. Non-invasive ventilation in exacerbations of COPD. Int J Chron Obstruct Pulmon Dis 2007;2(4):471-476.

6. Chandra D, Stamm JA, Taylor B, Ramos RM, Satterwhite L, Krishnan JA, Mannino D, et al. Outcomes of noninvasive ventilation for acute exacerbations of chronic obstructive pulmonary disease in the United States, 1998-2008. Am J Respir Crit Care Med 2012;185(2):152-159.

7. Weng CL, Zhao YT, Liu QH, Fu CJ, Sun F, Ma YL, et al. Metaanalysis: noninvasive ventilation in acute cardiogenic pulmonary edema. Ann Intern Med 2010;152(9):590-600.

8. Galindo-Filho VC, Dornelas-de-Andrade A, Brandão DC, de Cássia S Ferreira R, Menezes MJ, Almeida-Filho P, Parreira VF, et al. Noninvasive ventilation coupled with nebulization during asthma crises: a randomized controlled trial. Respir Care 2013;58(2):241-249.

9. Jolliet P, Abajo B, Pasquina P, Chevrolet JC. Non-invasive pressure support ventilation in severe community-acquired pneumonia. Intensive Care Med 2001;27(5):812-821.

10. Sharma S, Agarwal R, Aggarwal AN, Gupta D, Jindal SK. A survey of noninvasive ventilation practices in a respiratory ICU of North India. Respir Care 2012;57(7):1145-1153.

11. Redondo Calvo FJ, Madrazo M, Gilsanz F, Uña R, Villazala R, Bernal G. Helmet noninvasive mechanical ventilation in patients with acute postoperative respiratory failure. Respir Care 2012;57(5):743-752.

12. Hess DR. The growing role of noninvasive ventilation in patients requiring prolonged mechanical ventilation. Respir Care 2012;57(6): 900-918.

13. Su CL, Chiang LL, Yang SH, Lin HI, Cheng KC, Huang YC, Wu CP. Preventive use of noninvasive ventilation after extubation: a prospective, multicenter randomized controlled trial. Respir Care 2012; 57(2):204-210.

14. Anjos CF, Schettino GP, Park M, Souza VS, Scalabrini Neto A. A randomized of noninvasive positive end expiratory pressure in patients with acquired immune deficiency syndrome and hypoxemic respiratory failure. Respir Care 2012;57(2):211-220.

15. Figueroa-Casas JB. Preventive use of noninvasive ventilation after planned extubation (editorial). Respir Care 2012;57(2):318-320.

16. Collaborative Research Group of Noninvasive Mechanical Ventilation for Chronic Obstructive Pulmonary Disease. Early use of noninvasive positive pressure ventilation for acute exacerbations of chronic obstructive pulmonary disease: a multicentre randomized controlled trial. Chin Med J (Engl) 2005;118(24):2034-2040.
17. Paus-Jenssen ES, Reid JK, Cockcroft DW, Laframboise K, Ward HA. The use of noninvasive ventilation in acute respiratory failure at a tertiary care center. Chest 2004;126(1):165-172.

18. Burns KE, Sinuff T, Adhikari NK, Meade MO, Heels-Ansdell D, Martin CM, Cook DJ. Bilevel noninvasive positive pressure ventilation for acute respiratory failure: survey of Ontario practice. Crit Care Med 2005;33(7):1477-1483.

19. Maheshwari V, Paioli D, Rothaar R, Hill NS. Utilization of noninvasive ventilation in acute care hospitals: a regional survey. Chest 2006;129(5):1226-1233.

20. Kacmarek RM, Villar J. Acute application of noninvasive ventilation outside the ICU: when is it safe? (editorial) Respir Care 2012;57(5): 815-816.

21. Plant PK, Owen JL, Elliott MW. Early use of non-invasive ventilation for acute exacerbations of chronic obstructive pulmonary disease on general respiratory wards: a multicentre randomised controlled trial. Lancet 2000;355(9219):1931-1935.

22. Farha S, Ghamra ZW, Hoisington ER, Butler RS, Stoller JK. Use of noninvasive positive-pressure ventilation on the regular hospital ward: experience and correlates of success. Respir Care 2006;51(11):12371243.

23. Tamanna S, Ullah MI. Use of non-invasive ventilation in general ward for the treatment of respiratory failure. J Miss State Med Assoc 2011;52(9):278-281

24. McLaughlin KM, Murray IM, Thain G, Currie GP. Ward-based noninvasive ventilation for hypercapnic exacerbations of COPD: a reallife perspective. QJM 2010;103(7):505-510.

25. Cabrini L, Antonelli M, Savoia G, Landriscina M. Non-invasive ventilation outside of the Intensive Care Unit: an Italian survey. Minerva Anestesiol 2011;77(3):313-322.

26. Gould D. Promoting patient safety: the rapid medical response team. Perm J 2007;11(3):26-34.

27. Cabrini L, Idone C, Colombo S, Monti G, Bergonzi PC, Landoni G, et al. Medical emergency team and non-invasive ventilation outside ICU for acute respiratory failure. Intensive Care Med 2009;35(2):339-343.

28. Schneider AG, Calzavacca P, Mercer I, Hart G, Jones D, Bellomo R. The epidemiology and outcome of medical emergency team call patients treated with non-invasive ventilation. Resuscitation 2011; 82(9):1218-1223.

29. Knaus WA, Draper EA, Wagner DP, Zimmerman JE. APACHE II: a severity of disease classification system. Crit Care Med 1985; 13(10):818-829.

30. Elliott MW, Confalonieri M, Nava S. Where to perform noninvasive ventilation? Eur Respir J 2002;19(6):1159-1166.

31. Nava S, Confalonieri M, Rampulla C. Intermediate respiratory intensive care units in Europe: a European perspective. Thorax 1998; 53(9):798-802.

32. Criner GJ, Kreimer DT, Tomaselli M, Pierson W, Evans D. Financial implications of noninvasive positive pressure ventilation (NPPV). Chest 1995;108(2):475-481.

33. Laurens N, Dwyer T. The impact of medical emergency teams on ICU admission rates, cardiopulmonary arrests and mortality in a regional hospital. Resuscitation 2011;82(6):707-712.

34. Stelfox HT, Hemmelgarn BR, Bagshaw SM, Gao S, Doig CJ, Nijssen-Jordan C, Manns B. Intensive care unit bed availability and outcomes for hospitalized patients with sudden clinical deterioration. Arch Intern Med 2012;172(6):467-474.

This article is approved for Continuing Respiratory Care Education credit. For information and to obtain your CRCE

(free to AARC members) visit www.rcjournal.com

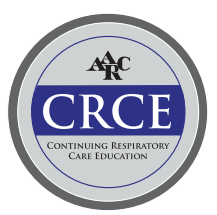

